\title{
Comprometimento profissional e estressores percebidos por graduandos regulares e tecnológicos
}

\author{
Alzira Pimentel Bondan \\ Universidade Federal do Rio Grande do Sul, Porto Alegre-RS, Brasil \\ Marucia Patta Bardagi \\ Universidade Luterana do Brasil, Santa Maria-RS, Brasil
}

\begin{abstract}
Resumo: Este estudo investigou o comprometimento com a carreira e os eventos estressores percebidos em 86 universitários (51 de cursos regulares e 35 de cursos tecnológicos) de uma instituição privada de ensino superior do Rio Grande do Sul. Os participantes eram homens $(81,4 \%)$ e mulheres entre 18 e 52 anos $(M=25,3 ; D P=8,16)$. Os resultados apontaram maior percepção de estressores entre os alunos de cursos tecnológicos $(t=3,02 ; g l=73 ; p<0,01)$ e maior comprometimento com a carreira entre os homens do que entre as mulheres $(t=2,49 ; g l=18 ; p<0,05)$. Estes dados indicam que ao mesmo tempo em que apresentam maior contato com o mercado e maior conhecimento da realidade ocupacional da área de formação, diminuindo a necessidade de intervenções voltadas à transição escola-trabalho, os alunos de cursos tecnológicos enfrentam maiores dificuldades no cotidiano universitário e na integração entre as tarefas acadêmicas e profissionais. Assim, são necessárias intervenções de carreira específicas a este público.
\end{abstract}

Palavras-chave: Estudantes. Estress. Ensino superior. Desenvolvimento profissional.

\section{Career commitment and stressors perceived by regular and technologic undergraduate students}

\begin{abstract}
This study investigated career commitment and stressors perceived by 86 undergraduate students (51 from regular courses and 35 from technologic ones) at a private university in Rio Grande do Sul, Brazil. Participants were men (81.4\%) and women between 18 and 52 years old $(M=25.3 ; S D=8.16)$. Results showed higher level of perceived stressors in technologic students $(t=3.02 ; d f=73 ; p<0.01)$ and higher levels of career commitment in men $(t=2.49 ; d f=18 ; p<0.05)$. These results suggest that even though technologic students have more contact with the job market and higher knowledge of the occupational status in their field, which decreases the need of interventions focused on the school-work transition, they face more difficulties in daily university tasks and in conciliating academic and professional demands. Therefore, specific interventions for this public are necessary.
\end{abstract}

Keywords: Students. Stress. Higher education. Professional development.

\section{Comprometimiento con la carrera y factores de estrés percibidos en estudiantes regulares y tecnológicos}

Resumen: Este estudio investigó el comprometimiento con la carrera y los estrés percibidos en 86 estudiantes ( 51 de cursos regulares y 35 de cursos tecnológicos) de una institución de enseño superior privada del Rio Grande do Sul. Los participantes eran hombres (81.4\%) y mujeres entre 18 y 52 años $(M=25,3 ; D P=8,16)$. Los resultados señalaran niveles mas altos de percepción de estrés entre los alumnos de los cursos tecnológicos $(t=3,02 ; d f=73 ; p<0,01)$ y niveles mas altos de comprometimiento entre los hombres $(t=2,49 ; d f=18 ; p<0,05)$. Estos resultados indican que los estudiantes tecnológicos tienen más contacto con el mercado laboral y un conocimiento más alto de la realidad ocupacional en su campo, pero hacen frente a más dificultades en las tareas diarias de la universidad y en la integración del académico y el profesional. Por lo tanto, las intervenciones específicas para este público son necesarias.

Palabras clave: Estudiantes. Estrés. Educación superior. Desarrollo profesional. 
Entre os aspectos que mais preocupam os profissionais de orientação profissional e de carreira no âmbito universitário estão os índices de evasão e insatisfação (insucesso) encontrados entre os alunos, considerados altos e preocupantes. Alguns autores defendem a necessidade de conhecer suas causas e implementar medidas preventivas (Almeida \& Soares, 2003; Pascarella \& Terenzini, 1991). Quando os jovens ingressam na universidade defrontam-se com uma série de desafios pessoais, interpessoais, familiares e institucionais. A permanência ou não do aluno até o final do curso depende especialmente de como a universidade trabalhará essa adaptação, tanto no curso como no espaço físico da instituição. A transição do ensino médio para o superior suscita inúmeras expectativas positivas, mas também uma série de receios e dificuldades aos jovens (Almeida \& Soares, 2003; Barker \& Schultz, 1992; Pachane, 2004). Um estudo recente aponta que entre as razões para evasão estão a falta de informações consistentes sobre as profissões e sobre o mundo universitário em geral, além de pouca identidade com a área de trabalho (Bardagi, 2007).

Alguns alunos ingressam na universidade sem ter conhecimento prévio sobre o curso que escolheram, pois às vezes as escolhas procuram atender às pressões familiares, ou porque o curso está em voga. Já outros, recém saídos do ensino médio, entram para o ensino superior alicerçados em projetos vocacionais mal definidos, o que constitui provavelmente um dos fatores para o insucesso, a inadaptação, a insatisfação e o abandono do curso. Experiências no contexto universitário sugerem que até mesmo alguns universitários ainda buscam uma solução para sua problemática vocacional. Como aponta Correia (2003), após o ingresso na universidade, o jovem pode começar a se defrontar com dificuldades que o levam a resultados não esperados, fazendo-o provar sentimentos tais como a desilusão e a frustração com o curso escolhido. É um momento difícil para o aluno e, nesse sentido, é necessário acesso a redes de apoio institucionais, a fim de minimizar o risco de desistência do curso, por exemplo.

Nesse sentido, seria importante que as universidades se preocupassem com os alunos que estão ingressando, pois os primeiros semestres são decisivos na efetivação do estudante ao curso. Quando ele se sente acolhido pela instituição em todos os sentidos, sua adesão ao curso se torna mais fácil (Bardagi, 2007; Diniz \& Almeida, 1997; Feitosa, 2001; Santos \& Melo-Silva, 2003; Teixeira, 2002). Em Portugal, por exemplo, assim como em outros países da Europa, como Alemanha, Noruega, França, entre outros, tem sido cada vez mais notória a preocupação com questões relativas à prestação de apoio aos estudantes de ensino superior, destacando-se o foco no apoio pedagógico e psicológico no início do curso (Santos, 2000).

A adaptação à universidade pode ser entendida como um processo multidimensional, envolvendo aspectos institucionais, relacionais, vocacionais, dentre outros. Ela requer o desenvolvimento, por parte do aluno, de um conjunto de competências adaptativas a um contexto não apenas novo, como também dinâmico em si mesmo (Barker \& Siryk, 1989). O aluno quando entra na universidade precisa muito mais do que se adaptar ao currículo propriamente dito e às normas institucionais. Neste momento, é importante uma estrutura que integre desde a recepção do aluno no seu primeiro dia na universidade, o seu acolhimento pela instituição e pela coordenação do curso, além do contato com os professores que deverão saber trabalhar a interação entre os novos alunos. Os programas de inserção ao ambiente acadêmico devem ter o principal propósito de envolver o aluno com a instituição, apresentando a ele os setores e os serviços que são oferecidos para o seu bem estar dentro da universidade. Para diversos autores, o envolvimento em atividades acadêmicas fora das aulas, a interação com os serviços e o grupo de funcionários e professores da universidade, assim como o relacionamento com os colegas, são aspectos que desempenham um importante papel a esse propósito (Granado, Santos, Almeida, Soares, \& Guisande, 2005; Kuh, Vésper, Connoly, \& Pace, 1997; Pascarella \& Terenzini, 1991).

Dois aspectos que parecem importantes para a manutenção do vínculo do aluno com o curso e a instituição são o comprometimento com a carreira, ou seja, a vinculação emocional com o curso e intenção de permanência nele, e a percepção de estressores, isto é, a avaliação de tarefas ou situações que fragilizam a escolha, pois são consideradas dificuldades intransponíveis. Conforme resultados de 
um estudo recente com universitários (Bardagi, 2007), o comprometimento com a carreira mostrou-se positivamente associado à exploração vocacional e satisfação com a profissão, além de negativamente associado à probabilidade de evasão. Ainda, um maior comprometimento com a carreira esteve associado à avaliação mais positiva do mercado de trabalho, existência de projetos futuros, menor percepção de estressores e melhor avaliação do próprio desempenho. Esses resultados apontam para um contexto de favorecimento do desenvolvimento de carreira, em que o comprometimento indicaria realmente maior identificação psicológica do indivíduo com a profissão, as atitudes que ele toma em benefício de sua profissão e o apego e estabelecimento de metas em longo prazo em relação à carreira, tal como descrito na literatura (Blau, 1985; Bastos, 1994).

Com relação aos eventos estressores, cada indivíduo se comporta de maneira diferente em situação de estresse, um único estressor não poderá levar o indivíduo ao estresse, mas sim a combinação e o acúmulo de vários agentes. Como define Seger (2001), o estresse, em termos de adaptação, é como uma resposta não específica do organismo a qualquer mudança ambiental, em que o organismo tenta adaptar-se, elaborar um comportamento na presença de uma situação, face à qual seus padrões habituais de referência encontram-se superados, de modo que o seu repertório pessoal de respostas comportamentais se revela insuficiente (Seger, 2001). As fontes de estresse são classificadas em externas e internas; as externas não dependem unicamente do controle do indivíduo, pois envolvem eventos, doenças, mudanças inesperadas que exigem algum tipo de adaptação, problemas do cotidiano, além de outros. Já as fontes internas estão diretamente ligadas à pessoa, como vulnerabilidade, baixa assertividade, dentre outros (Lipp, 1996; Lipp \& Malagris, 1998). No contexto universitário, os estudos costumam apontar como estressores mais freqüentes aqueles que revelam discrepância entre as expectativas que o aluno tem e a realidade observada na universidade. Por exemplo, decepção com conteúdos de disciplinas, desapontamento com professores, falta de motivação e dificuldade em relacionar os conteúdos com a prática profissional (Bardagi, 2007). A percepção de estressores costuma estar negativamente relacionada à satisfação com o curso e à profissão e positivamente relacionada com a probabilidade de evasão (Bardagi, 2007).

De forma geral, as pesquisas com estudantes universitários que têm como foco a carreira e o desenvolvimento vocacional são ainda incipientes no Brasil, mais raros são os estudos que avaliam as diferenças no desenvolvimento psicossocial e de carreira entre alunos regulares e alunos de cursos tecnológicos. Grande parte dos conhecimentos acerca do desenvolvimento vocacional de universitários foi concebido a partir de estudos com alunos de graduação tradicional (Bardagi, 2007; Santos \& MeloSilva, 2003; Teixeira, 2002). No entanto, por estarem em outro tipo de formação superior, é possível supor que as trajetórias e o envolvimento acadêmico possam seguir direções particulares para os alunos de cursos tecnológicos.

As graduações tecnológicas surgiram para suprir uma demanda crescente no mundo do trabalho, que exige maior preparação, formação e aprimoramento educacional e profissional, dentro de um espaço de tempo menor. O tecnólogo é um profissional de nível superior, que deve estar apto a desenvolver atividades em uma determinada área, sua formação é direcionada à aplicação, desenvolvimento e difusão de tecnologias, em sintonia com o mundo do trabalho. De uma forma mais rápida e eficiente o curso deve atender ao anseio dos jovens de obter competências para as diversas modalidades no mercado de trabalho, qualificando-o, por meio do domínio de tecnologias atualizadas, para o exercício da profissão. O ensino tecnológico, assim como a graduação, exige que o aluno tenha concluído o ensino médio. $\mathrm{O}$ tempo de duração é menor, pode ir de dois anos e meio a três anos e é especificamente voltado ao mercado de trabalho. Aos que já são graduados, o curso oferece a oportunidade de ampliação ou de diversificação de sua atuação profissional (Brasil, 2007). Não devem ser confundidos com os cursos técnicos, pois estes são de nível médio e não permitem ao formando continuar seus estudos em cursos de pós-graduação. Os cursos tecnológicos foram criados para responder às novas tendências do mercado que cada vez mais exige profissionais com perfil diferenciado, dotado de competências e habilidades específicas. Ao concluir um 
curso tecnológico o formando poderá ingressar em um curso de pós-graduação lato sensu (especialização) ou stricto sensu (mestrado/doutorado), ou mesmo optar por outro curso de graduação, aproveitando os estudos já realizados (Universidade Cidade de São Paulo [UNICID], 2007).

No Brasil, o número de cursos tecnológicos aumentou muito de 1994 a 2004, por volta de 591\% (Instituto Nacional de Estudos e Pesquisas Educacionais Anísio Teixeira [INEP], 2006). O número de cursos de 2004 até o momento de realização desta pesquisa passou de 1.804 a 3.548 , além disso, o número de matriculados e concluintes também teve aumento considerável. Por ser uma graduação mais curta e voltada para a prática, cada vez mais, se firma como uma opção dos estudantes. No entanto, existe certa desconfiança ainda em relação aos cursos tecnológicos por parte dos jovens e também das empresas empregadoras, na verdade, há grande desconhecimento por parte de ambos sobre o que significa essa modalidade de curso.

Há no Brasil uma "cultura do bacharelado", que valoriza apenas o diploma de cursos tradicionais de graduação. Uma medida para reafirmar a identidade do tecnólogo foi a criação de catálogos pelo Ministério da Educação (MEC), em cumprimento ao Decreto $n^{\circ}$ 5.773/06. Estes se apresentam como um guia aos estudantes, educadores e instituições ofertantes, sistemas e redes de ensino, entidades representativas de classes, empregadores e o público em geral.

Desde os últimos anos, a partir do próprio investimento do Ministério da Educação, houve um aumento na procura por cursos tecnológicos no Brasil. No entanto, apesar do crescimento dos cursos tecnológicos e do número de alunos inscritos e concluintes destes cursos, não houve um paralelo desenvolvimento de estudos de acompanhamento destes alunos. Assim como acontece com os cursos de graduação tradicionais, nos cursos tecnológicos é possível imaginar que o alunado enfrente dificuldades de adaptação à universidade e necessite de intervenções facilitadoras dos processos de transição escola-universidade e universidade-trabalho. Há, portanto, uma crescente necessidade de conhecer com profundidade e extensão o comportamento vocacional do indivíduo durante o período da formação superior e tecnológica, tradicionalmente um contexto negligenciado pelas pesquisas, embora fundamental para a consolidação da identidade profissional e a elaboração de projetos futuros. A partir destas considerações, e da possível diferença ainda não mapeada entre o desenvolvimento de alunos de graduações tradicionais e graduações tecnológicas, esta pesquisa teve como objetivo investigar os níveis de comprometimento com a carreira e as situações vivenciadas pelos alunos e consideradas estressoras.

\section{Método}

\section{Participantes}

Participaram 86 estudantes universitários de uma instituição privada da Grande Porto Alegre, divididos em dois grupos: 51 alunos de cursos regulares e 35 alunos de cursos tecnológicos, das mesmas áreas de formação (sistemas de informação - 39,5\% alunos regulares e $24 \%$ tecnológicos; e administração de empresas - 19,8\% regulares e 16,3\% tecnológicos). Os participantes eram homens $(81,4 \%)$ e mulheres entre 18 e 52 anos $(M=25,3 ; D P=8,16)$, cursando os semestres iniciais dos respectivos cursos no segundo semestre de 2007. A maioria era de indivíduos solteiros $(70,9 \%)$, que moravam com os pais $(54,7 \%) \mathrm{e}$ estavam em sua primeira graduação $(70,9 \%)$. A maioria possuía atividade remunerada $(81,4 \%)$, sendo que destes $62,8 \%$ exercem atividades relacionada com o curso. A média de idade dos participantes é mais alta entre os alunos de cursos tecnológicos $(t=-2,02 ; g l=83$; $p<0,05)$.

\section{Instrumentos}

No presente estudo, foram utilizados os seguintes instrumentos:

(1) Questionário sócio-demográfico $e$ vocacional, que buscou coletar informações sobre características pessoais, familiares, sócio-econômicas e ocupacionais (atividades acadêmicas, trabalho, planos futuros).

(2) Escala de Comprometimento com a Carreira de Blau (1985) adaptada para o Brasil por Bastos (1994), um instrumento unidimensional de sete itens, de tipo Likert de cinco pontos, com avaliação somatória, em que o estudante aponta o quanto as 
afirmativas refletem o modo como se sente em relação à profissão/carreira. Neste estudo foi utilizada uma versão modificada da escala para estudantes universitários, com troca do termo carreira pelo termo profissão nos itens, já utilizada anteriormente (Bardagi, 2007) com bom índice de consistência interna, a saber, Alpha de Cronbach de 0,89. O comprometimento pode ser descrito como o sentimento de conexão com a área de estudo, o estabelecimento de metas em relação a ela e a intenção de permanecer na área, constituindo uma boa medida indicativa de permanência ou tendência à evasão.

(3) Escala de Estressores Vocacionais (Bardagi $\&$ Hutz, 2005), instrumento composto de 18 itens distribuídos em uma escala Likert de cinco pontos. Os alunos são solicitados a identificar com que freqüência as situações já ocorreram com eles. A escala, cuja avaliação é somatória, foi criada para um estudo anterior (Bardagi, 2007) e demonstrou boa consistência interna, com Alpha de Cronbach de 0,83.

\section{Procedimento}

Inicialmente, foi solicitada autorização da IES (Instituição de Ensino Superior) para realização da pesquisa e foram feitos contatos com as coordenações dos cursos a fim de esclarecer os objetivos da pesquisa e solicitar a participação das mesmas na amostra. Após aceite, foram marcadas datas e horários, de acordo com a disponibilidade dos professores responsáveis pelas disciplinas iniciais dos cursos, para aplicação dos instrumentos. Os participantes responderam aos instrumentos em aplicações realizadas coletivamente em sala de aula. Cada sessão de aplicação foi precedida de uma breve explicação dos objetivos do estudo. A participação no estudo foi voluntária, sendo solicitada aos participantes a assinatura do Termo de Consentimento Livre e Esclarecido. O estudo foi aprovado pelo Comitê de Ética do Curso de Psicologia da Universidade Federal do Rio Grande do Sul.

\section{Resultados}

Inicialmente, as escalas psicométricas apresentaram bons índices de consistência interna, com Alpha de Cronbach de 0,77 para o instrumento de comprometimento com a carreira e 0,83 para o de eventos estressores. As respostas ao questionário só- cio-demográfico e vocacional identificaram que, na amostra total, com relação a ter planos após terminar a graduação, 61,6\% afirmaram ter planos já definidos, $25,6 \%$ ainda estavam em dúvida e $12,8 \%$ não sabiam o que pretendiam fazer; ainda, $83,7 \%$ disseram que nunca pensaram em desistir da profissão, enquanto 16,3\% disseram já ter pensado em desistir ou mudar de profissão. Quando questionados sobre quais os tipos de atendimentos que julgam necessários para esse momento, o item construção de projeto profissional foi o que teve um percentual mais alto (66,3\%), seguido de necessidade de informações sobre a área de formação (59,3\%), instrumentalização para busca de trabalholestágio $(32,6 \%)$, criação de currículo (25,6\%), re-orientação profissional e integração ao ambiente universitário (índices de $11,6 \%$ cada um).

Ao se comparar os alunos de acordo com o tipo de graduação (regular e tecnológica), a partir do teste $\mathrm{t}$ de student, não houve diferença de médias em relação ao comprometimento com a carreira $(p<0,8)$; já em relação à percepção de estressores, os alunos de cursos tecnológicos apresentaram média mais alta do que alunos de cursos regulares $(t=3,02 ; g l=73 ; p<0,01)$. Quanto ao gênero, também se utilizando o teste $t$ de student para comparação de médias, percebeu-se que há maior comprometimento com a carreira entre os homens do que entre as mulheres $(t=2,49 ; g l=18$; $p<0,05)$. Com relação à percepção de estressores não houve diferença de gênero $(p<0,7)$. Testes de associação Qui-quadrado não mostraram associações entre gênero e tipos de intervenções (citados anteriormente) em orientação profissional ou existência de planos futuros. Entre tipo de formação (regular ou tecnológica) e planos futuros também não houve associação, mas com relação às intervenções observou-se que os alunos de cursos regulares solicitaram mais auxílio para construção de currículo e elaboração de projeto profissional do que os alunos de cursos tecnológicos $\left(X^{2}=3,99 ; g l=1 ; p<0,05 ; X^{2}=4,01 ; g l=1 ; p<0,05\right.$, respectivamente).

A descrição dos eventos estressores mais freqüentes nos dois grupos está apresentada na Tabela 1 . Os estressores menos freqüentes em ambos os grupos foram Conflito/brigas com colegas, Greves, paralisações e Experiência de relacionamento "frio", "distante" com os professores. 
Tabela 1

Estressores mais freqüentes percebidos por alunos regulares e tecnológicos

\begin{tabular}{ll}
\hline Alunos de cursos regulares & $15,7 \%$ \\
\hline 15 - Falta de tempo para se dedicar ao curso, aos estudos & $11,8 \%$ \\
3 - Falta de motivação para estudar ou freqüentar as aulas & $5,9 \%$ \\
11 - Falta de entrosamento com os colegas & \\
8 - Experiências insatisfatórias de estágio ou trabalho & $4 \%$ \\
13 - Incompatibilidade entre a estrutura do curso e seu estilo de vida & \\
14 - Sentimento de que o curso não prepara para o trabalho & $20,6 \%$ \\
16 - Percepção de que o curso não é essencial para a atividade a ser desempenhada & $17,7 \%$ \\
17 - Diferença de crenças e valores em relação aos colegas e professores & $17,6 \%$ \\
\hline Alunos de cursos tecnológicos & $15,2 \%$ \\
\hline 1 - Decepção com conteúdos das disciplinas & $14,7 \%$ \\
15 - Falta de tempo para se dedicar ao curso, aos estudos & \\
2 - Dificuldade em relacionar os conteúdos e a prática profissional & \\
3 - Falta de motivação para estudar ou freqüentar as aulas & \\
4 - Desempenho insatisfatório nas disciplinas & \\
14 - Sentimento de que o curso não prepara para o trabalho & \\
\hline
\end{tabular}

\section{Discussão}

Este estudo teve por objetivo comparar os índices de comprometimento com a carreira e percepção de estressores entre alunos de cursos regulares e tecnológicos. De forma geral, os resultados indicaram mais conformidade do que diferenças entre os dois grupos, talvez em função da formação em áreas semelhantes. Ainda, é um dos primeiros estudos com estudantes de cursos tecnológicos que têm como foco o desenvolvimento de carreira destes alunos. Inicialmente, é preciso salientar que o perfil geral dos alunos pesquisados distancia-se da caracterização do universitário típico brasileiro. A maioria dos participantes, apesar de solteiro e ainda morando com os pais, está acima da média de idade ( 25 anos) esperada para um universitário em primeira graduação e já possui atividade remunerada (mais de $80 \%$ ). Ainda, é bastante representativo o número de alunos casados ou em união estável que moram com suas famílias, sendo responsáveis pelo sustento da casa. Esse perfil é mais comum em universidades privadas, como a que serviu de base para coleta de dados desta pesquisa, e demonstra que o aluno universitário compõe um grupo bastante heterogêneo e com necessidades específicas, conforme apontado por vários estudos recentes com amostras universitárias (Bardagi, 2007; Teixeira, 2002). A maior presença de homens na amostra também não é compatível com o número geral de homens e mulheres no ensino superior (Brasil, 2007), mas deve-se principalmente ao tipo de cursos selecionados para o estudo. Inicialmente, em função das características dos dois tipos de cursos, poder-se-ia pensar que os alunos de cursos tecnológicos fossem mais velhos, com um menor percentual de solteiros, com maior índice de atividades remuneradas e que já não estivessem em sua primeira graduação. No entanto, os perfis de alunos regulares e tecnológicos se aproximaram, à exceção da média de idade, realmente maior entre os alunos de cursos tecnológicos.

As análises com a amostra geral indicam que mesmo em uma etapa inicial dos cursos, a maioria dos alunos já tem planos definidos sobre o que fazer após a graduação. Este resultado, embora positivo e indicativo da existência de projetos profissionais que guiem o percurso acadêmico, deve ser visto com cautela. Outros estudos já apontaram que nos períodos iniciais do curso os alunos tendem a ser mais oti- 
mistas em relação à profissão e sustentar projetos mais fantasiosos, pouco consistentes, baseados em informações às vezes estereotipadas sobre a carreira e o curso (Bardagi, 2007; Feitosa, 2001; Santos, 2000; Santos \& Melo-Silva, 2003; Teixeira, 2002). Um outro resultado que corrobora essa idéia de que no início do curso os projetos podem ser ainda incipientes e pouco estruturados é a solicitação que os alunos fazem de auxílio à construção do projeto profissional e informações sobre a área de formação; estas foram as intervenções mais frequientes entre os participantes da pesquisa. Isso demonstra a necessidade percebida pelos alunos de propostas de intervenção mais instrumentalizadoras, que venham a contribuir para a consolidação das metas iniciais de carreira e suprir as lacunas da exploração vocacional (busca de informações relevantes à carreira) feita antes da entrada no curso. Estas intervenções podem, por exemplo, ser estruturadas dentro das próprias grades curriculares, em disciplinas introdutórias que facilitem a exploração de informações de carreira relevantes sobre os cursos, além da consolidação das intervenções de orientação vocacional oferecidas aos adolescentes e jovens adultos anteriormente à entrada na universidade.

Quanto às análises relativas ao comprometimento com a carreira, os resultados indicaram diferenças significativas de gênero, em que as mulheres apresentaram menor comprometimento do que os homens, independentemente do tipo de graduação. Este resultado não confirma outros achados envolvendo universitários, que não mostram diferenças de gênero no comprometimento (Bardagi, 2007). No entanto, é preciso levar em conta dois aspectos ao compreender esses resultados. O primeiro, já mencionado anteriormente, é a maior quantidade de alunos homens na amostra, o que pode ter influenciado o resultado, o outro é a natureza mais técnica dos cursos que participaram do estudo. Embora as áreas de informática e administração de empresas não sejam, já há muito tempo, terrenos limitados ao universo masculino, a natureza técnica das atividades e os conteúdos mais direcionados às áreas de exatas e lógica costuma ser mais atrativos aos homens do que às mulheres, segundo estudos sobre preferências profissionais (Tilleczek \& Lewko, 2001). Nesse sentido, a sensação de segurança quanto à escolha, perspectivas mais consistentes de permanência e maior identificação com o curso talvez estejam mais presentes nos homens, ao constatarem que os cursos oferecem conteúdos próximos aos interesses tradicionais masculinos. O nível de certeza de carreira costuma aparecer relacionado aos interesses consistentes com papéis sexuais tradicionais (McMahon \& Patton, 1997; Schulenberg, Goldstein, \& Vondracek, 1991; Stockard \& Mgee, 1990). As mulheres, embora se afastem menos de profissões tipicamente masculinas do que os homens de profissões tipicamente femininas (Maxwell, Maxwell, \& Krugly-Smolska, 1996), são descritas como tendo maior interesse pela dimensão social do trabalho - possibilidade de intervenção social, contato interpessoal, benefício social, dentre outros. Como o estudo foi feito nos semestres iniciais, talvez estes conteúdos (também presentes nos cursos de administração e análise de sistemas) ainda não tivessem sido discutidos mais amplamente, em detrimento de conteúdos mais teóricos e técnicos, o que auxiliou um maior desengajamento feminino.

A percepção de estressores, ao contrário, não apontou diferenças de gênero, mas sim de tipo de graduação, tanto no nível de estressores quanto no tipo. Os estressores menos freqüentes, em ambos os grupos, são aqueles esperados em uma universidade privada, por exemplo, greves e paralisações, e aqueles que indicam bons relacionamentos interpessoais, o que é um bom prognóstico de adaptação acadêmica (Almeida \& Soares, 2003; Granado e cols., 2005; Kuh e cols., 1997; Pascarella \& Terenzini, 1991). Os alunos dos cursos tecnológicos apresentaram níveis mais altos de percepção de estressores do que os alunos de graduação tradicional. Esse resultado pode ser entendido a partir das diferenças de perfil entre os grupos. Os alunos dos cursos tecnológicos são mais velhos, a maioria com família própria, já inseridos no mercado de trabalho e provavelmente afastados dos estudos há mais tempo do que os alunos de cursos regulares. Dessa forma, a estrutura da universidade, as exigências acadêmicas e a rotina da graduação talvez tragam maiores dificuldades para eles, criando um descompasso entre as expectativas iniciais e a realidade universitária. 
Os estressores mais freqüentes entre os alunos de cursos tecnológicos apontam essa distância. Mesmo que os cursos tecnológicos tenham um enfoque mais direcionado ao mercado (Brasil, 2007), há diferenças entre um ensino de nível superior e um curso técnico, com ênfase na formação global do indivíduo e aprendizagem de conteúdos mais teóricos, o que pode desagradar aos alunos que já trabalham na área e esperam apenas complementação técnica. É possível que essa decepção com as disciplinas esteja vinculada ao fato de que a maior experiência profissional pode ter influenciado o tipo de expectativa que o aluno tem em relação ao curso. Nesse sentido, é preciso preparar os alunos de cursos tecnológicos para a formação superior e para as exigências próprias que ela demanda. Ainda, não se pode negar a possibilidade de realmente os cursos tecnológicos estarem defasados em relação à realidade do mercado sendo, portanto, necessário que façam uma reavaliação de sua estrutura curricular e pedagógica. Outras queixas mais frequientes entre os alunos de cursos tecnológicos são a falta de tempo e o mau desempenho, também possivelmente consequiências das exigências do trabalho externo, cuidados com família e a falta de familiaridade com as formas de avaliação e rotinas acadêmicas.

Como os estudos existentes sobre o tema costumam apontar as relações entre estressores, percepção de problemas e insatisfação com o curso e evasão (Bardagi, 2007; Pachane, 2004), é preciso que as universidades fiquem atentas aos alunos de cursos tecnológicos e elaborem estratégias de intervenção preventivas ao abandono de curso. Ao contrário do que se conhece da realidade dos alunos universitários jovens, que ingressam no ensino superior talvez sem segurança das escolhas de carreira realizadas e sem a maturidade necessária para enfrentar as exigências da vida acadêmica (Diniz \& Almeida, 1997; Feitosa, 2001; Pascarella \& Terenzini, 1991; Santos \& Melo-Silva, 2003; Teixeira, 2002), os alunos de cursos tecnológicos enfrentam dificuldades vindas das múltiplas responsabilidades que têm, e da falta de familiaridade com os processos e rotinas acadêmicas, o que também pode levar a um desengajamento progressivo com o curso.

\section{Considerações finais}

Através desse trabalho de pesquisa foi possível avançar um pouco mais no estudo de algumas necessidades manifestadas pelos alunos universitários e que algumas vezes não são observadas pelas universidades. Há um grande sentimento dos alunos pesquisados de que as duas graduações, regular e tecnológica, não preparam para o mundo do trabalho e a percepção de que o curso não é essencial para a atividade a ser desempenhada. Essas percepções, ainda que fruto de informações estereotipadas ou expectativas irrealistas quanto às profissões, devem servir como material de reflexão para as unidades de ensino, no sentido de que é necessário auxiliar o aluno a identificar as relações entre o que está sendo aprendido e as atividades a serem desenvolvidas no futuro. No entanto, é preciso fazer algumas ressalvas. Inicialmente, este é um estudo exploratório, que contou com a participação de um número pequeno de estudantes de apenas uma instituição de ensino superior. É preciso que novos estudos com amostras mais amplas, de cursos de áreas distintas, possam confirmar ou descrever novas informações sobre o desenvolvimento de carreira dos alunos de cursos tecnológico. Ainda, para uma compreensão mais ampla da realidade vivenciada por estes alunos, levantamentos qualitativos sobre a experiência acadêmica de alunos de cursos tecnológicos podem contribuir para a elucidação de questões como as diferenças de gênero no comprometimento de carreira, as dificuldades apontadas pelo levantamento de estressores, entre outros aspectos.

De forma geral, no entanto, percebe-se a necessidade, também em relação a este público, de serviços de acompanhamento universitário. Algumas universidades já oferecem alguns serviços importantes para os alunos ingressantes, como oficinas para nivelamento em que são sanadas dúvidas advindas da educação básica e que dificultam que o aluno tenha um bom desempenho acadêmico, uma vez que esse é de fundamental importância para a efetivação do aluno ao curso. Além disso, intervenções que venham a auxiliar o aluno a superar as dificuldades contextuais, interpessoais e também vocacionais podem formar uma rede de apoio importante para sua permanência no curso e para a diminuição dos níveis de estresse e descontentamento. Acreditar que somente um Projeto Político Pedagógico bem estruturado e um currículo minuciosamente planejado são elementos suficientes para o sucesso acadêmico do aluno e de garantia para a instituição de ensino, infelizmente é uma utopia. 
Acredita-se que estes aspectos, aliados a uma boa proposta de trabalho que envolva o aluno em todas as suas dimensões, poderiam ser bons preditores de sucesso. Nesse sentido, é necessário que as intervenções sejam criadas com base nas necessidades reais dos alunos, para que o resultado seja produtivo e instrumentalizador.

\section{Referências}

Almeida, L. S., \& Soares, A. P. (2003). Os estudantes universitários: Sucesso escolar e desenvolvimento psicossocial. In E. Mercuri \& S. A. J. Polydoro (Orgs.), Estudante universitário: Características e experiências de formação (pp. 15-40). Taubaté, SP: Cabral.

Bardagi, M. P. (2007). Evasão e comportamento vocacional de universitários: Estudos sobre o desenvolvimento de carreira na graduação. Tese de Doutorado não-publicada, Programa de Pós-graduação em Psicologia do Desenvolvimento, Universidade Federal do Rio Grande do Sul, Porto Alegre, RS.

Bardagi, M. P., \& Hutz, C. S. (2005). Escala de estressores vocacionais. Manuscrito não-publicado, Instituto de Psicologia, Universidade Federal do Rio Grande do Sul, Porto Alegre, RS.

Barker, R. W., \& Schultz, K. L (1992). Experiential counterparts of test-indicated disillusionment during freshman adjustment to college. NACADA Journal, 12(2), 13-22.

Barker, R. W., \& Siryk, B. (1989). SACQ Student Adaptation to College Questionnaire

Manual. Western Psychology, 11, 333-346.

Bastos, A. V. B. (1994). Comprometimento no trabalho: A estrutura dos vínculos do trabalhador com a organização, a carreira $e$ o sindicato. Tese de doutorado não-publicada, Programa de Pós-graduação em Psicologia, Universidade de Brasília, Brasília, DF.

Blau, G. J. (1985). The measurement and prediction of career commitment. Journal of Occupational and Organizational Psychology, 58, 277-288.
Brasil. Ministério da Educação. Secretaria de Educação profissional e tecnológica. (2007). Legislação de cursos tecnológicos. Recuperado em 19 setembro 2007, de http://portal.mec.gov.br/setec.

Correia, T. (2003). O insucesso académico no IST. Lisboa: Gabinete de Estudos e Planejamento, Instituto Superior Técnico.

Diniz, A. M., \& Almeida, L. S. (1997). Construção de uma escala de qualidade da integração no ensino superior (EQIES). Psicologia: Teoria, Investigação e Prática, 2, 85-96.

Feitosa, M. G. G. (2001). Integração de estudantes ingressantes à vida universitária: Fatores que facilitam e que dificultam sua integração. Tese de doutorado não-publicada, Faculdade de Educação, Universidade Federal de São Carlos, São Carlos, SP.

Granado, J. I. F., Santos, A. A. A., Almeida, L., Soares, A. P., \& Guisande, M. A. (2005). Integração acadêmica de estudantes universitários: Contributos para a adaptação e validação do QVA-r no Brasil. Psicologia e Educação, 4(2), 33-43.

Instituto Nacional de Estudos e Pesquisas Educacionais Anísio Teixeira [INEP]. (2006). Censo da Educação Superior. Recuperado em 19 setembro 2007, de http://www.inep.gov.br/superior/ censosuperior/default.asp

Kuh, G. D., Vesper, N., Connoly, M. R., \& Pace, C. R. (1997). College student experiences questionnaire: Revised norms for the 3rd edition. Bloomington, IN: Indiana University Center for Postsecondary Research and Planning.

Lipp, M. E. N. (1996). Stress: Conceitos básicos. In M. E. N. Lipp (Org.), Pesquisas sobre o stress no Brasil: Saúde, ocupações e grupos de risco (pp. 17-29). Campinas, SP: Papirus.

Lipp, M. E. N., \& Malagris, L. N. (1998). Manejo do stress. In B. Rangé (Org.), Psicoterapia comportamental e cognitiva: Pesquisa, prática, aplicações e problemas (pp. 279-291). Campinas, SP: Editorial Psy 
Maxwell, M. P., Maxwell, J. D., \& Krugly-Smolska, E. (1996). Ethnicity, gender, and occupational choice in two Toronto schools. Canadian Journal of Education, 21(3), 257-279.

McMahon, M., \& Patton, W. (1997). Gender differences in children and adolescents' perceptions of influences on their career development. School Counselor, 44(5), 368-376.

Pachane, G. G. (2004). A experiência universitária e sua contribuição ao desenvolvimento pessoal do aluno. In E. Mercuri \& S. A. J. Polydoro (Orgs.), Estudante universitário: Características e experiências de formação (pp. 155-186). Taubaté, SP: Cabral.

Pascarella, E. T., \& Terenzini, P. T. (1991). How college affects students. San Francisco: Jossey-Bass.

Santos, L. T. M. (2000). Vivências acadêmicas $e$ rendimento escolar: Estudos com alunos universitários do $1^{\circ}$ ano. Dissertação de mestrado não-publicada, Universidade do Minho, Braga, Portugal.

Santos, M. A., \& Melo-Silva, L. L. (2003). Será que era isso o que eu queria? A formação acadêmica em psicologia na perspectiva do aluno. In L. L. Melo-Silva, M. A. Santos, \& J. T. Simões (Orgs.), Arquitetura de uma ocupação: Vol. 1. Orientação profissional: Teoria e técnica (pp. 387-406). São Paulo: Vetor.

Schulenberg, J., Goldstein, A. E., \& Vondracek, F. W. (1991). Gender differences in adolescents' career interests: Beyond main effects. Journal of Research on Adolescence, 1, 37-61.

Seger, L. (2001). O stress e seus efeitos no profissional, na equipe e no paciente odontológico. In M. L. Marinho \& V. E. Caballo (Orgs.), Psicologia clínica e da saúde (pp. 213-223). Londrina, PR: EdUEL.

Stockard, J., \& Mcgee, J. (1990). Children's occupational preferences: The influence of sex and perceptions of occupational characteristics. Journal of Vocational Behavior, 36, 287-303.
Teixeira, M. A. P. (2002). A experiência de transição entre a universidade e o mercado de trabalho na adultez jovem. Tese de doutorado não-publicada, Programa de Pós-graduação em Psicologia do Desenvolvimento, Universidade Federal do Rio Grande do Sul, Porto Alegre, RS.

Tilleczek, K. C., \& Lewko, J. H. (2001). Factors influencing the pursuit of health and science careers for Canadian adolescents in transition from school to work. Journal of Youth Studies, 4, 415-428.

Universidade Cidade de São Paulo. (2007). Relatório cursos tecnológicos Universidade Cidade de São Paulo. Recuperado em 21 outubro de 2007, de http://www.unicid.br/cgi/cgilua.exe/sys/ start.htm?sid=187

Artigo recebido em 09/05/2008.

Aceito para publicação em 23/11/2008.

O presente artigo refere-se ao trabalho de conclusão de curso de Especialização em Psicologia Clínica, ênfase em Orientação Profissional, da Universidade Federal do Rio Grande do Sul, de autoria da primeira autora, sob orientação da segunda autora.

Endereço para correspondência:

Profa. Dra. Marucia Patta Bardagi. Universidade Luterana do Brasil. Curso de Psicologia. BR 287, Km 252, Trevo Maneco Pedroso. CEP 97020-001. Santa Maria- RS, Brasil. E-mail: marucia.bardagi@gmail.com

Alzira Pimentel Bondan é especializanda em Orientação Profissional pela Universidade Federal do Rio Grande do Sul.

Marucia Patta Bardagi é Professora Adjunta do curso de Psicologia da Universidade Luterana do Brasil, Santa Maria. 